\title{
Multi-objective Water Resources Optimum Allocation Scheme Based on Improved Standard Cuckoo Searching Algorithm (ISCSA)
}

Ke Zhou ( $\square$ zhouke828282@163.com )

North China University of Water Resources and Electric Power https://orcid.org/0000-0001-5347-6318

\section{Research Article}

Keywords: The standard cuckoo searching algorithm(SCSA), the improved standard cuckoo searching algorithm (ISCSA); Multi-objective Optimization Model, Water Resources Optimal allocation Scheme, Case Study.

Posted Date: April 5th, 2021

DOI: https://doi.org/10.21203/rs.3.rs-192405/v1

License: (c) (i) This work is licensed under a Creative Commons Attribution 4.0 International License.

Read Full License 


\title{
Multi-objective Water Resources Optimum Allocation Scheme Based on Improved Standard Cuckoo Searching Algorithm(ISCSA)
}

\author{
Ke Zhou, Dean \\ Tianjin University. Tianjin. 300072. China. \\ North China University of Water Resources and Electric Power. \\ Jinshui Road 136, Zhengzhou, Henan, 450046. China. \\ Email address: zhouke828282@163.com \\ ORCID ID; 0000-0001-5347-6318
}

Received: 2021; Accepted; 2021; Published:

Acknowledgments: The study was supported by the Natural Science Fund of China

Short title: Study on Improved Standard Cuckoo Searching Algorithm and its application

Abstract: The standard cuckoo searching algorithm (SCSA) is a population intelligent optimization algorithm, which is also a new heuristic searching algorithm. The advantages of SCSA (such as convenient operation, heuristic searching, etc.) make it easy to find the optimal solution and maintain wider searching range. However, SCSA also has some drawbacks, such as long searching time, easy to fall into local optimum. In order to solve the problems existed in SCSA, in this paper, the improved standard cuckoo searching algorithm (ISCSA) was studied, which includes chaotic initialization and Gaussian disturbed algorithm. As a case study, taking economic, social and ecological benefits as the objective function, the multi-objective water resources optimal allocation models were constructed in Xianxiang Region, China. The ISCSA was applied to solve the water allocation models and the multi-objective optimal water supply scheme for Xinxiang region was obtained. The water resources optimal allocation schemes in the planning level year (2025) for 12 water supply sub-regions were predicted. The desirable eco-environment and benefits were achieved using the studied methods. The results show that the ISCSA has obvious advantages in the solution of water resources optimal allocation and planning. 
Keywords: The standard cuckoo searching algorithm(SCSA); the improved standard cuckoo searching algorithm (ISCSA); Multi-objective Optimization Model; Water Resources Optimal allocation Scheme; Case Study.

\section{Highlights:}

- The improved standard cuckoo searching algorithm (ISCSA) was studied to overcome the disadvantages of the standard cuckoo searching algorithm (SCSA);

- The superiority of ISCSA algorithm was tested and comparisons were made among different functions;

- A typical region of China was selected and the multi-objective water resources optimal allocation models were constructed and solved using ISCSA;

- The desirable results were achieved by using the studied methods.

\section{Graphical abstract}

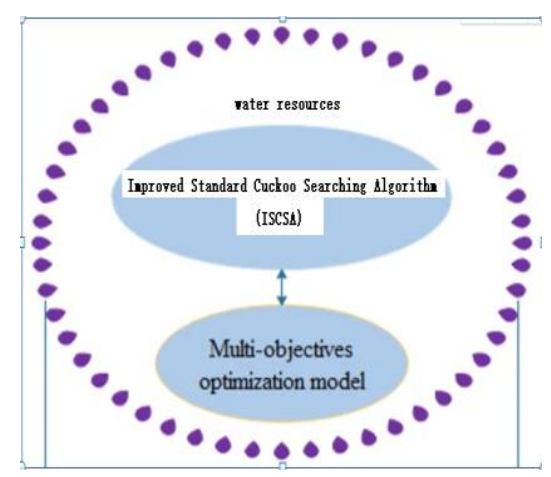

\section{Introduction}

With the development of social economy and population, the problems of water supply and demand are becoming more and more prominent. Due to climate change, drought and flood disasters occur alternately, which causes great losses to social economy. Therefore, the optimal water resources allocation has been become an important research topic in home or abroad (Whited, et al. 2012, Chen et al. 2019).

During recent years, in order to find effective water resources allocation algorithm, a lot of new algorithms were studied by the related researchers, such as particle swarm optimization(Civicioglu 
P, Besdok E .2013)、social emotion optimization algorithm(SEOA) (Chen, et al. 2019; Fallah, et al. 2019)、 self-adaptive multi-objective harmony search(Choi et al. 2017)、fast network multi-objective design algorithm (Creaco E, Franchini M . 2012)、genetic algorithm(Deb K et al. 2002)、shuffled frog leaping algorithm (Eusuff, Lansey 2003)、 harmony search optimization(Geem, Kim, Loganathan 2002), etc. The above algorithms belong to intelligent algorithms, which are used to solve the optimal water resources allocation models, and good results have been obtained. However, most intelligent algorithms have the following disadvantages(Kaveh A, Bakhshpoori T 2016, Kivijärvi J, Fränti P, Nevalainen 2003); many uncertainty parameters and complex determinations; poor local searching ability, etc. The optimal solution is easy to wander near the final scheme and leads to the fast convergence rate. Compared with other intelligent algorithms, the advantages of standard cuckoo searching algorithm (SCSA) are relative few parameters, simple programming, few revised parameters in practical problems, and fast convergence (Mohammad et al. 2019, Montalvo I,et al. 2010),etc.

However, SCSA algorithm has some drawbacks, such as long searching time, easy to fall into local optimum(Moosavian N, Lence 2017, Naidu MN, et al.2020). In the process of high dimensional function optimization, there exist problems of slow convergence and low optimization precision (Prasad, Park 2004). During recent years, the SCSA algorithm has been applied in many fields including water resources optimal allocation, but the effect is still unsatisfactory (Saleh SH, Tanyimboh TT 2014). Therefore, in order to solve the problems existed in SCSA algorithm, in this paper, the improvement on SCSA was studied. Firstly, chaos initialization conditions were introduced. In initial stage, we try to keep the bird's nest position in the solution space as evenly as possible to improve the operation efficiency. Secondly, Gauss disturbance is added to make the algorithm maintain ability to jump out of local optimum. Finally, as a case study, Xinxiang water supply region of China was selected. The optimal water resources allocation models were constructed based on water distribution systems in the region. The ISCSA algorithm is applied to solve the optimal water resources allocation models in the region. The desirable schemes have been 
achieved, which can support the local water resources reasonable utilization and social economic development.

\section{Materials and methods}

\subsection{Standard cuckoo searching algorithm (SCSA)}

The standard cuckoo searching algorithm ( SCSA) is a population intelligent optimization algorithm, which is also a new heuristic searching algorithm(Salman A, et al. 2007, Solihin MI, Zanil MF 2016). It was proposed by Professor Yang in 2009(Tanyimboh TT, Czajkowska A 2018).

SCSA algorithm has the advantages of convenient operation, easy to find the optimal solution and wider searching range path(Vasan A, Simonovic SP 2010). The main idea of SCSA is based on two strategies, i.e. the breeding and feeding behavior of cuckoo and the flight mechanism(Yang XS 2014).

\subsection{Improved standard cuckoo searching algorithm (ISCSA)}

(1) Chaotic Initialization

Because of the bird's nest uneven distribution and influence of the initialization settings, there exists strong randomness in the SCSA. Therefore, the chaotic cubic mapping was put forward to initialize the bird's nest, in this way, the distribution of the SCSA in the specific solution space can be maintained with a certain rule so as to establish the foundation for the effective global searching.

Logistic mapping is a typical chaotic system, the expressions are as follows,

$$
\left\{\begin{array}{c}
\mathrm{y}(\mathrm{n}+1)=\mu \mathrm{y}(\mathrm{n})(1-\mathrm{y}(\mathrm{n})), 0<y(n)<1) \\
0<\mu \leq 4, i=0,1,2, \ldots
\end{array}\right.
$$

in which, $\mu$ is control variable, when $\mu=4$, through Logistic mapping, entire chaotic status could be realized, then, the initial cuckoo nest position generated by chaotic iteration is optimized to make the next pairing searching, the steps are as follows,

- For $\mathrm{N}$ bird's nest locations in $\mathrm{D}$ dimension space, a D dimension vector is randomly generated and 
recorded as the first nest position, i.e. $Y_{1}^{0}=\left(y_{1}, y_{2}, \ldots, y_{d}\right)$, in which, $y_{i} \in(0,1), 1 \leq i \leq d$.

- N-1 iterations are carried out for each dimension in each nest, then, $N-1$ bird's nests could be generated, i.e. $\mathrm{Y}_{2}^{(0)}, \ldots, \mathrm{Y}_{\mathrm{N}-1}^{(0)}, \mathrm{Y}_{\mathrm{N}}^{(0)}$.

-After all the bird nest iterations are finished, mapping the results to the solution space using Eq.2.

$$
\mathrm{x}_{\mathrm{id}}=\mathrm{L}_{\mathrm{id}}+\left(1+\mathrm{y}_{\mathrm{id}}\right) \frac{\mathrm{U}_{\mathrm{d}}-\mathrm{L}_{\mathrm{d}}}{2}
$$

where, $\mathrm{L}_{\mathrm{id}}$ is the Logistic mapping of the $d$ th dimension in the $i$ th nest, $U_{\mathrm{d}}$ and $L_{\mathrm{d}}$ represent the upper and lower bounds of the $d$ th dimension in the searching space, yid is the $d$ th dimension of the $i$ th nest in the searching space, Xid represents the coordinates of the $i$ th nest at the $d$ th dimension searching space.

Firstly, the chaotic Logistic mapping is used to initialize the bird's nest position so that it could be evenly distributed in the solution space. Secondly, the position of the first bird nest is used to adjust the adaptive step size. When it is far from the initial bird's nest position, the larger step size will be selected to search the optimum solution. The step size calculation is shown in Eq. 3.

$$
\text { step interval }=\text { rand } \times\left\|x_{i}-\mathrm{X}_{\text {location }}\right\|
$$

in which, rand is a random number between 0 and $1, x_{i}$ is a bird location in the solution space, $\mathrm{X}_{\text {location }}$ represents the current location of the initial nest.

Thirdly, in the process of cuckoo bird nest selection, the maximum number of cuckoo nest selection and the change of the first nest location are used as the end conditions. The recognition distance method in the original algorithm is no longer used, which could improve the operation speed of the algorithm.

\section{(2) Gaussian Disturbances}

In the standard cuckoo search algorithm (SCSA), it is easy to fall into local optimum, in fact, most of intelligent algorithms are difficult to jump out of the local optimal solution, which results in undesirable conclusion(Yasar M 2016). Therefore, in this paper, Gaussian micro-disturbance are 
performed to the former nest position for each iteration, as follows,

$$
\begin{aligned}
& \mathrm{G}_{\text {best }}=\mathrm{G} \times(1+\operatorname{Gaussian}(\mu, \sigma)) \\
& \mathrm{G}^{\mathrm{t}+1}=\left\{\begin{array}{c}
\mathrm{NG}_{\text {best }}^{\mathrm{t}}, f\left(\mathrm{NG}_{\text {best }}^{\mathrm{t}}\right)<f\left(\mathrm{G}^{\mathrm{t}}\right) \\
\mathrm{G}^{\mathrm{t}}, \text { others }
\end{array}\right.
\end{aligned}
$$

Where, Gaussian(.) is the function of Gaussian, $G^{t}$ is the adaptive value of the former nest, that is, the adaptation value of the former nest before disturbance, $N G_{b e s t}^{t}$ is the adaptive value of the former bird nest after disturbance.

The micro disturbance for $G_{\text {best }}$ could jump out of the local optimum domain to make systematic analysis, the efficiency and accuracy of the entire algorithm can be improved desirably, which could be helpful to increase the diversity of bird nest and improve the accuracy of solution (Razmkh et al. 2010, Ladon et al. 1999).

\subsection{Algorithm validation}

In order to test the superiority of ISCSA algorithm, six standard functions (see Table 1) were selected as the benchmark function(Wang et al. 2015, Zheng et al. 2013, OMID R G et al. 2014), in which $f_{1} \sim f_{3}$ are single peak functions, $f_{4} \sim f_{6}$ are multi-peak functions.

\begin{tabular}{|c|c|c|c|}
\hline functions & formulas & Scope & $\begin{array}{c}\text { Theoretical } \\
\text { optimal } \\
\text { solution }\end{array}$ \\
\hline Sphere & $f_{1}(x)=\sum_{i=1}^{n} x_{i}^{n}$ & {$[-100,100]$} & 0 \\
\hline $\begin{array}{l}\text { Schwefel's } \\
2.22\end{array}$ & $f_{2}(x)=\sum_{i=1}\left|x_{i}\right|+\prod_{i=1}\left|x_{i}\right|$ & {$[-10,10]$} & 0 \\
\hline Schwefel's 1.2 & $\sum_{i=1} \sum_{j=1}$ & {$[-100,100]$} & 0 \\
\hline Rastrigin & $f_{4}(x)=\sum\left[x_{i}^{2}-10 \cos \left(2 \pi x_{i}\right)+10\right]$ & {$[-5.12,5.12]$} & 0 \\
\hline Ackley & $f_{5}(x)=-20 \exp \left(-0.2 \mid \frac{1}{n} \sum x_{i}{ }^{2}\right)-\exp \left(\frac{1}{n} \sum \cos \left(2 \pi x_{i}\right)\right)+20+e$ & {$[-32,32]$} & 0 \\
\hline Griewank & $f_{6}(x)=\frac{1}{4000} \sum_{i=1}^{n} x_{i}^{2}-\prod_{i=1}^{n} \cos \left(\frac{x_{i}}{\sqrt{i}}\right)+1$ & {$[-600,600]$} & 0 \\
\hline
\end{tabular}

\section{Table 1 Test functions}

The performance of ISCSA algorithm was tested using Matlab. The intelligent algorithms of genetic 
algorithm (GA) and particle swarm optimization (PSO) were used to compare with ISCSA algorithm. The parameters of the algorithm are set as follows: population base number, maximum iteration number and function dimensions. Each test functions are optimized for 20 times, and according to the test results (best, worst, average, standard deviation), ISCSA algorithm can be evaluated. The comparison and test results can be seen in Table2.

Table2 Comparison of test results

\begin{tabular}{|c|c|c|c|c|c|}
\hline functions & algorithms & best & worst & average & standard deviation \\
\hline \multirow[t]{4}{*}{ Sphere } & GA & 8.23E-06 & $3.90 \mathrm{E}-02$ & $7.00 \mathrm{E}-03$ & $9.00 \mathrm{E}-03$ \\
\hline & PSO & $1.46 \mathrm{E}-08$ & $3.51 \mathrm{E}-04$ & 4.92E-05 & $8.68 \mathrm{E}-05$ \\
\hline & SCSA & $7.65 \mathrm{E}-43$ & 4.70E-39 & $2.08 \mathrm{E}-39$ & $2.26 \mathrm{E}-39$ \\
\hline & ISCSA & 4.32E-130 & $7.72 \mathrm{E}-128$ & $7.18 \mathrm{E}-129$ & $2.62 \mathrm{E}-128$ \\
\hline \multirow[t]{4}{*}{ Schwefel's 2.22} & GA & $2.30 \mathrm{E}-03$ & $3.14 \mathrm{E}-01$ & $1.02 \mathrm{E}-01$ & 8.30E-02 \\
\hline & PSO & $2.58 \mathrm{E}-05$ & $6.51 \mathrm{E}-01$ & $6.40 \mathrm{E}-02$ & 2.37E-01 \\
\hline & SCSA & $3.20 \mathrm{E}-24$ & $9.18 \mathrm{E}-23$ & $1.95 \mathrm{E}-23$ & $2.25 \mathrm{E}-23$ \\
\hline & ISCSA & $3.06 \mathrm{E}-74$ & $2.05 \mathrm{E}-71$ & $3.22 \mathrm{E}-72$ & $5.70 \mathrm{E}-71$ \\
\hline \multirow[t]{4}{*}{ Schwefel's 1.2} & GA & $3.08 \mathrm{E}-06$ & $2.57 \mathrm{E}-02$ & $8.60 \mathrm{E}-03$ & $1.90 \mathrm{E}-02$ \\
\hline & PSO & 5.02E-08 & $2.88 \mathrm{E}-04$ & 5.15E-05 & 5.82E-05 \\
\hline & SCSA & $3.23 \mathrm{E}-45$ & $2.88 \mathrm{E}-42$ & $5.03 \mathrm{E}-43$ & $6.13 \mathrm{E}-43$ \\
\hline & ISCSA & $2.47 \mathrm{E}-141$ & $2.53 \mathrm{E}-135$ & $1.46 \mathrm{E}-136$ & $4.86 \mathrm{E}-136$ \\
\hline \multirow[t]{4}{*}{ Rastrigin } & GA & 3.09E-04 & $9.56 \mathrm{E}-01$ & 3.17E-01 & $4.25 \mathrm{E}-01$ \\
\hline & PSO & 7.03E-05 & $4.09 \mathrm{E}+00$ & $1.40 \mathrm{E}+00$ & $1.82 \mathrm{E}+00$ \\
\hline & SCSA & $4.26 \mathrm{E}-14$ & $3.07 \mathrm{E}-11$ & $3.48 \mathrm{E}-12$ & $6.70 \mathrm{E}-12$ \\
\hline & ISCSA & 0 & 0 & 0 & 0 \\
\hline \multirow[t]{4}{*}{ Ackley } & GA & $6.30 \mathrm{E}-04$ & $1.15 \mathrm{E}-01$ & 4.10E-02 & 4.30E-02 \\
\hline & PSO & $1.13 \mathrm{E}-05$ & 8.20E-02 & $1.50 \mathrm{E}-02$ & $2.60 \mathrm{E}-02$ \\
\hline & SCSA & $1.21 \mathrm{E}-05$ & $1.72 \mathrm{E}-04$ & 4.83E-05 & $6.82 \mathrm{E}-05$ \\
\hline & ISCSA & $1.13 \mathrm{E}-15$ & $1.13 \mathrm{E}-15$ & $1.13 \mathrm{E}-15$ & $1.08 \mathrm{E}-15$ \\
\hline \multirow[t]{4}{*}{ Griewank } & GA & 3.20E-08 & $7.30 \mathrm{E}-02$ & $1.60 \mathrm{E}-02$ & $2.10 \mathrm{E}-02$ \\
\hline & PSO & $1.41 \mathrm{E}-10$ & $1.11 \mathrm{E}+00$ & 4.77E-01 & $5.38 \mathrm{E}-01$ \\
\hline & SCSA & $7.65 \mathrm{E}-12$ & $1.73 \mathrm{E}-08$ & 2.91E-09 & 4.52E-09 \\
\hline & ISCSA & 0 & 0 & 0 & 0 \\
\hline
\end{tabular}

According to Table2, in single peak function $f_{1} \sim f_{3}$, the optimization ability of the different algorithms is ISCSA> SCSA $>\mathrm{PSO}>\mathrm{GA}$, with the optimal values increased by more than $50 \%$, which indicates that the optimization ability could be greatly improved by using the ISCSA. It is because that the optimization ability of GA algorithm is very limited, which could only be improved 
through mutation operation to create new solution space. In multi-peak function $f_{4} \sim f_{6}$, The optimization ability of the algorithm is, in turn, ISCSA $>$ SCSA $>$ GA $>$ PSO. It is because that the PSO algorithm is easy to fall into the local optimal solution, in fact, the optimal value of the PSO algorithm is better than that of the GA algorithm, but the overall level of the PSO keeps low compared with the GA algorithm. The ISCSA algorithm has the characteristics of Levitt's performance, which can effectively expand the exploring range and have strong global exploring ability, so that it has the highest optimization ability than other algorithms. Since there are calculation errors in the matlab software, the ISCSA algorithm can reach to 0 both in the multi-peak function Rastrigin and Griewank, which indicates that the ISCSA algorithm can effectively achieve the global optimal solution. Here, selecting the multi-peak function Rastrigin as a test function, the convergence process of four algorithms were drawn in Fig.1.

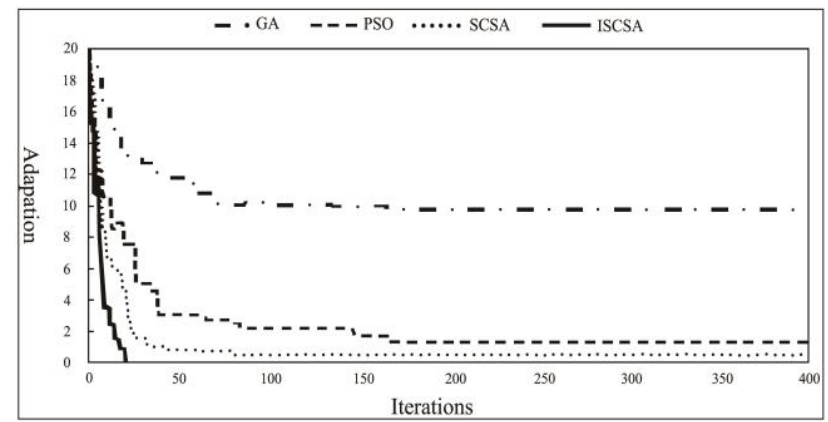

Fig.1 Convergence process diagram of different algorithms

It can be seen from Fig.1 that convergence speed of the ISCSA is the fastest in all algorithms and the best results are realized. Therefore, it can be concluded that the convergence accuracy and global optimization ability of ISCSA are obviously better than that of SCSA, and the best optimization effect can be achieved by using ISCSA algorithm in solving optimal models.

\section{Case study}

\subsection{Background}

The Xinxiang water supply region of China was selected as an example in this paper. The region is located on the north bank of the lower reaches of the Yellow River, with the geographical 
coordinates $\mathrm{N} 34^{\circ} 53^{\prime} \sim \mathrm{N} 35^{\circ} 50^{\prime}, \mathrm{E} 113^{\circ} 23^{\prime} \sim \mathrm{E} 115^{\circ} 01^{\prime}$. The region covers 12 water supply sub-regions with the total area of $8249 \mathrm{~km}^{2}$. The Xinxiang water supply region has a total population of 6130000, of which 2940000 are rural and 3190000 are urban population. The annual average precipitation is $580 \mathrm{~mm}$. The annual average natural water resources in Xinxiang region is 1697.0 million $\mathrm{m}^{3}$, of which surface water resources accounts for 744.0 million $\mathrm{m}^{3}$ and underground water resources accounts for 953.0 million $\mathrm{m}^{3}$. In 2018, agricultural effective irrigation area in the region reached to $335400 \mathrm{hm}^{2}$, urbanization rate was $52 \%$.

\subsection{Water resources optimal allocation scheme based on ISCSA}

\subsubsection{Water resources system optimization allocation nodes design}

Based on the distribution of water supply project system and water demand (domestic, industrial and agricultural production and eco-environment) in the region, and considering natural water resources components (such as surface and underground water), as well as the special water requirements of different sub-regions, the entire water supply region of Xinxiang can be divided into 12 sub-regions. The general nodes map of water supply in Xinxiang region is drawn as Fig 2.

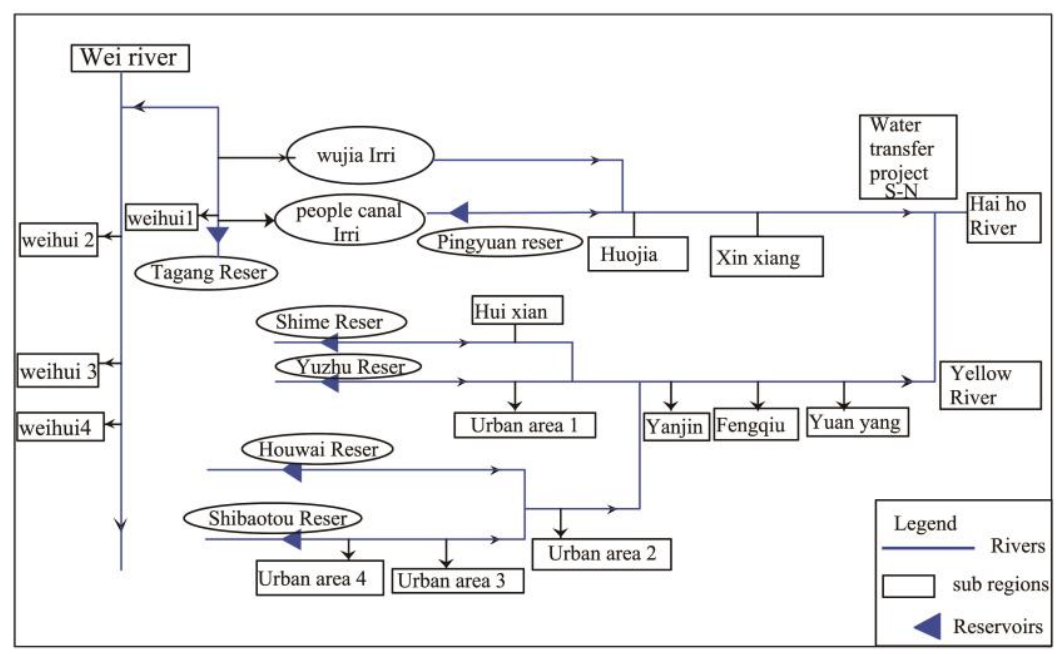

Fig.2 Generalization schematic of water supply nodes in Xinxiang water supply region

\subsubsection{Construction of water resources optimal allocation models}

\section{Objective functions}

(1) Economic objective

Maximizing economic benefit is one of the important goals for regional water resources allocation. 
The economic benefit can be calculated with Eq. 6 .

$$
\mathrm{f}_{1}(\mathrm{x})=\max \sum_{\mathrm{i}}^{\mathrm{I}} \sum_{\mathrm{j}}^{\mathrm{J}} \alpha_{\mathrm{ij}} \mathrm{x}_{\mathrm{ij}}
$$

where $\alpha_{i j}$ indicates the economic benefits generated by per unit water consumption of $\mathrm{j}$ water users in the $i$ th water supply sub-region, Yuan $/ \mathrm{m}^{3}, \mathrm{x}_{\mathrm{ij}}$ indicates the allocated water amount for the $\mathrm{jth}$ water user in the $i$ th water supply sub-region, $\mathrm{m}^{3}$. I,J indicate the total number of water supply sub-regions and the total number of water users, respectively.

(2) Social benefit objective

Here we use the minimum water shortage as the social economic objective, as Eq.7.

$$
f_{2}(x)=\min \sum_{i=1}^{I} \sum_{j=1}^{J} \beta_{j}\left(b_{i j}-x_{i j}\right)
$$

where $\beta_{\mathrm{j}}$ is weight coefficient of water shortage for the $\mathrm{jth}$ water user, 1 is for the first production sector; 2 is for the second production sector; 3 is for others, $b_{i j}$ is water requirement of the jth water user in the $i$ th water supply sub-region.

(3) Ecological benefit objective

The objective is to realize minimum pollutants emission, here, we select COD as an indicator.

$$
\mathrm{f}_{3}(\mathrm{x})=\min \left(\sum_{\mathrm{i}=1}^{\mathrm{I}} \sum_{\mathrm{j}=1}^{\mathrm{J}} 0.01 \delta_{\mathrm{ij}} \mathrm{p}_{\mathrm{ij}} \mathrm{x}_{\mathrm{ij}}\right)
$$

where $\delta_{i j}$ indicates the pollutants (COD) discharged by the jth water user per unit water consumption in the ith water supply sub-region, $\mathrm{t} / \mathrm{m}^{3}, P_{i j}$ indicates wastewater discharge coefficient of the $j$ th water user in the $i$ th water supply area, $\%, \mathrm{x}_{\mathrm{ij}}$ indicates the allocated water amount for the jth water user in the $i$ th water supply sub-region, $\mathrm{m}^{3}$.

\section{Constraints}

(1) The water supply capacity

$$
\sum_{\mathrm{i}=1}^{\mathrm{I}} \sum_{\mathrm{j}=1}^{\mathrm{J}} \mathrm{X}_{\mathrm{ij}} \leq \mathrm{W}-\mathrm{B}
$$

where $\mathrm{W}$ represents total amount of water supply, $\mathrm{m}^{3}$; $\mathrm{B}$ represents the minimum ecological water 
demand in river channels, $\mathrm{m}^{3}, \mathrm{x}_{\mathrm{ij}}$ indicates the allocated water amount for the $\mathrm{jth}$ water user in the $i$ th water supply sub-region, $\mathrm{m}^{3}$.

(2) Domestic water demand

According to the relevant policies, the domestic water demand should be firstly guaranteed, then,

$$
\sum_{\mathrm{i}=1}^{\mathrm{I}} \mathrm{X}_{\mathrm{id}}=\mathrm{X}_{\mathrm{D}}
$$

where $X_{D}$ is the total amount of domestic water supply, $\mathrm{m}^{3} ; \mathrm{x}_{\mathrm{id}}$ indicates the total amount of domestic water demand of the ith users.

(3) Pollutants emission control

According to the relevant regulations, water pollutants discharge should meet national and local standards.

$$
\sum_{\mathrm{i}=1}^{\mathrm{I}}(\mathrm{COD})_{\mathrm{i}} \leq(\mathrm{COD})_{\mathrm{N}}
$$

where $(\mathrm{COD})_{\mathrm{N}}$ indicates the national water pollutants control standard, $\mathrm{kg} / \mathrm{m}^{3}$. (COD) $)_{\mathrm{i}}$ is water pollutants volume of the $i$ th water user, $\mathrm{kg} / \mathrm{m}^{3}$.

(4) Ecological water use

Ecological water demand should be guaranteed firstly.

$$
\sum_{\mathrm{i}=1}^{\mathrm{I}} \mathrm{X}_{\mathrm{ie}}=\mathrm{X}_{\mathrm{E}}
$$

where $\mathrm{x}_{\mathrm{ie}}$ is the ecological water use for the ith water supply sub-region, $\mathrm{X}_{\mathrm{E}}$ is the total ecological water supply, $\mathrm{m}^{3}$.

(5) Maximum and minimum water demand

$$
\mathrm{X}_{\mathrm{ijmin}} \leq \mathrm{D}_{\mathrm{ij}} \leq \mathrm{X}_{\mathrm{ijmax}}, \mathrm{i}=1,2, \ldots, \mathrm{I} ; \quad \mathrm{j}=1,2, \ldots, \mathrm{J} \text {. }
$$

where $X_{i j \min }$ and $X_{i j \max }$ are the minimum and maximum water demand of $j$ th water users in the $i$ th water supply sub-region, and $\mathrm{D}_{\mathrm{ij}}$ is the water demand of the $\mathrm{jth}$ water user in the ith water supply 
sub-region.

(6) Water balance constraint

$$
\sum_{\mathrm{i}=1}^{\mathrm{I}} \sum_{\mathrm{j}=1}^{\mathrm{J}} \mathrm{X}_{\mathrm{ij}}=\mathrm{X}_{\mathrm{ij}}
$$

$\mathrm{X}_{\mathrm{ij}}$ is the total amount of water supply in Xinxiang region, $\mathrm{m}^{3}$.

(7) Non negative

$$
\sum_{\mathrm{i}=1}^{\mathrm{I}} \sum_{\mathrm{j}=1}^{\mathrm{J}} \mathrm{x}_{\mathrm{ij}} \geq 0
$$

\subsubsection{Water demand forecast}

According to the investigation on the experiment sub-regions, in 2025, average irrigation quota will reach to $3700.5 \mathrm{~m}^{3} / \mathrm{hm}^{2}$, average irrigation water utilization coefficient will be 0.601 . Domestic water use for urban residents will be $124.2 \mathrm{~L} / \mathrm{d}$.person. Domestic water use for rural residents will be 68.9L/d.person. the irrigation quota for forest and fruit trees will be $7230 \mathrm{~m}^{3} / \mathrm{hm}^{2}$. The irrigation area for forest and fruit trees will reach to $2530 \mathrm{hm}^{2}$. Fish pond area will reach to $3700 \mathrm{hm}^{2}$, which requires $11290.95 \mathrm{~m}^{3} / \mathrm{hm}^{2}$ for water replenishment. In animal husbandry sector, large livestock water demand quota will be $29 \mathrm{~L} / \mathrm{d} \cdot \mathrm{head}$, and small livestock water demand quota will be 15 L/d.head. In 2025, urbanization rate of Xinxiang region will reach to $58 \%$, public urban water consumption will reach to 58.67 million $\mathrm{m}^{3}$. Annual eco-environmental water demand will be increased by $10 \%$, thus, eco-environmental water demand will be 33.80 million $^{3}$ in 2025 . Table 1 shows the total water demand for different water supply sub-regions in 2025.

Table1 Water demand of Xinxiang Region in 2025(million $\left.\mathrm{m}^{3}\right)$

\begin{tabular}{llllcccccc}
\hline Sub-regions & Agricultue & industry & forestry & husbandry & fishery & Urban public & domestic & Eco-environment & Total \\
\hline urban & 68.8 & 89.2 & 1.3 & 0.4 & 2.2 & 22.6 & 60.4 & 15.7 & 260.6 \\
xinxiang & 96.4 & 77.3 & 0.0 & 0.9 & 2.70 & 3.0 & 19.0 & 2.7 & 202.0 \\
weihui & 96.2 & 20.8 & 0.0 & 4.3 & 3.9 & 5.2 & 16.0 & 2.6 & 149.0 \\
huixian & 152.9 & 90.2 & 3.2 & 5.4 & 1.6 & 9.2 & 24.8 & 2.2 & 289.5 \\
huojia & 122.6 & 20.5 & 8.2 & 1.8 & 4.7 & 3.4 & 14.7 & 2.3 & 178.2 \\
yuanyang & 216.0 & 23.0 & 0.0 & 2.9 & 8.2 & 3.3 & 19.5 & 1.8 & 274.7 \\
yanjin & 119.1 & 23.9 & 1.7 & 1.6 & 11.5 & 2.6 & 15.5 & 1.8 & 177.7 \\
fengqiu & 201.4 & 13.7 & 0.0 & 3.6 & 3.0 & 4.6 & 22.2 & 2.3 & 250.8 \\
changyuan & 167.8 & 41.4 & 3.7 & 1.9 & 3.5 & 4.9 & 26.4 & 2.4 & 252.0 \\
Total & 1241.2 & 400 & 18.1 & 22.8 & 41.4 & 58.7 & 218.5 & 33.8 & 2034.5 \\
\hline
\end{tabular}




\subsubsection{Model operation Results analysis}

According to the above models and water demand in the region, the ISCSA algorithm was used to search the water resources optimal allocation scheme. 200 seed groups were selected and 100 iterations were calculated. The water resources allocation schemes of Xinxiang water supply region in 2025 were optimized. The comparison of optimal results among different schemes can be seen in Fig.3 and Fig.4.

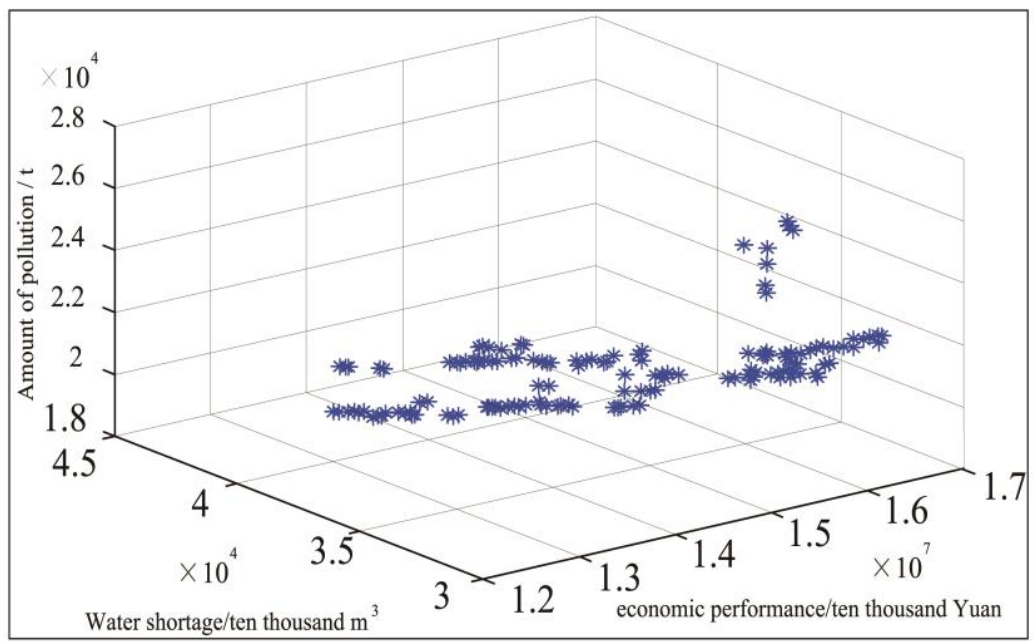

Fig. 3. Optimal solution set of SCSA algorithm

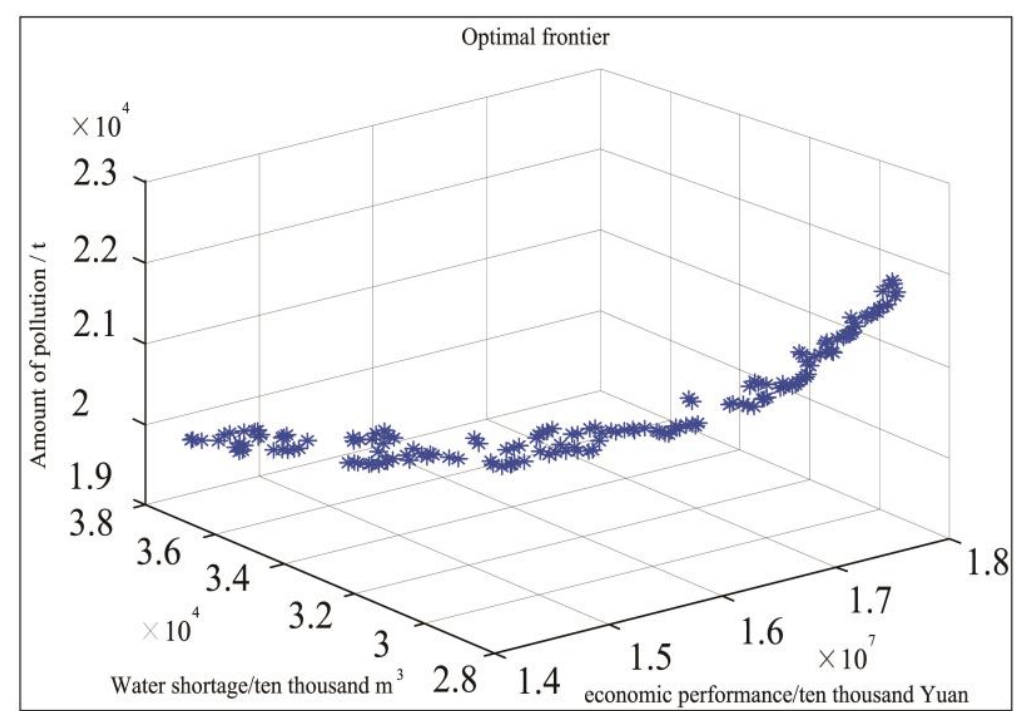

Fig. 4. Optimal solution set of ISCSA algorithm

Comparing with the SCSA algorithm in Fig .3, the optimal solution set generated by the ISCSA algorithm in Fig.4. is more uniform and close to a smooth curve, which shows that the results of ISCSA is better than that of SCSA. 


\subsubsection{The optimal allocation scheme of water resources in Xinxiang region}

Based on the water resources optimal allocation models (Eq.6 to Eq.15), and using the ISCSA algorithm, the optimal allocation scheme of water resources in Xinxiang water supply region can be achieved as Table2.

Table2 The water resources optimal allocation scheme in Xinxiang Region (million $\mathrm{m}^{3}$ )

\begin{tabular}{|c|c|c|c|c|c|c|c|c|c|c|}
\hline \multirow{3}{*}{ Sub-regions } & \multicolumn{3}{|c|}{ Water supply } & \multicolumn{4}{|c|}{ Increased water supply ability } & \multirow{3}{*}{$\begin{array}{l}\text { Total Water } \\
\text { Supply ability }\end{array}$} & \multirow{3}{*}{$\begin{array}{l}\text { Water } \\
\text { demand }\end{array}$} & \multirow{3}{*}{$\begin{array}{l}\text { Benefits } \\
\left(10^{8} \text { Yuan }\right)\end{array}$} \\
\hline & Surface & ground & Rain & rural & Urban & Sewage & S-N Water & & & \\
\hline & water & water & harvest & Water & Water & reuse & transfer & & & \\
\hline urban & 38.3 & 0.0 & 0 & 0.8 & 0 & 0.87 & 2.30 & 277.9 & 260.6 & 522.4 \\
\hline xinxiang & 30.3 & 113.7 & 0 & 0.4 & 0 & 0 & 57.6 & 202.0 & 202.0 & 379.9 \\
\hline weihui & 45.2 & 56.5 & 2.6 & 0.4 & 0 & 0 & 45.0 & 149.7 & 149.0 & 281.5 \\
\hline huixian & 60.6 & 163.9 & 10.3 & 1.9 & 0 & 0 & 57.5 & 294.2 & 289.5 & 553.3 \\
\hline huojia & 124.3 & 33.9 & 0 & 0.8 & 0 & 0 & 19.8 & 178.8 & 178.2 & 336.3 \\
\hline yuanyang & 250.0 & 11.5 & 0 & 1.6 & 15.0 & 0 & 0 & 278.1 & 274.7 & 523.0 \\
\hline yanjin & 57.8 & 106.4 & 0 & 0.8 & 1.0 & 0 & 0 & 166.0 & 177.7 & 312.2 \\
\hline fengqiu & 83.2 & 164.3 & 0 & 1.2 & 0 & 0 & 0 & 248.7 & 250.8 & 467.7 \\
\hline changyuan & 146.5 & 85.1 & 0 & 3.7 & 0 & 10.0 & 0 & 245.3 & 252.0 & 461.3 \\
\hline Total & 836.2 & 735.2 & 12.9 & 11.6 & 16.0 & 18.7 & 410.0 & 2040.7 & 2034.5 & 3837.6 \\
\hline
\end{tabular}

It shows in Table 2 that the total water supply ability can be raised to 2040.7 million $\mathrm{m}^{3}$ in 2025 .

The increased water supply ability includes rural water supply, urban water supply, water transfer from south to north, etc. Sewage water reuse will be increased to 18.7 million $\mathrm{m}^{3}$. Rain water collection and utilization will be increased to 12.9 million $\mathrm{m}^{3}$. Considering investigation on social and economic development in the region, the water resources utilization and benefits were calculated for the optimal allocation scheme. It can be seen form Table2 that the benefits (GDP) of Xinxiang region will reach to 383.76 billion Yuan in 2025. The benefits generated from the optimal water resources allocation scheme will be 153.5 billion Yuan RMB in 2025.

It can be seen from Table 2 that according to water resources optimal allocation scheme studied in this paper, the amount of groundwater exploitation will be reduced to 735.2 million $\mathrm{m}^{3}$ in 2025 , which means that 217.8 million $\mathrm{m}^{3}$ underground water resources were saved compared with that in 2009. Under the condition of strengthening water saving measures, the balance between water 
supply and demand in Xinxiang region can be realized. The water use for eco-environment will be 33.8 million $\mathrm{m}^{3}$ in 2025 , thus, the eco-environment will be improved greatly.

\section{Conclusions}

In this paper, the ISCSA algorithm was studied and applied to the multi-objective water resources allocation models to obtain water resources optimal allocation scheme in the studied region. The Deficiencies in the SCSA algorithm (such as easy falling into a local optimization in the searching process, long searching time, slow convergence and low optimization precision, etc.) have been overcome and the convergence speed of SCSA algorithm is accelerated.

The performance of ISCSA algorithm was tested using test functions(Sphere, Schwefel's 2.22, Schwefel's 1.2, Rastrigin, Ackley, Griewank). The intelligent algorithms of genetic algorithm (GA) and particle swarm optimization (PSO) were used to compare with ISCSA algorithm.

It can be concluded that convergence speed of the ISCSA should be faster than other methods. The desirable results were realized by using ISCSA algorithm. It can also be concluded that the accuracy and global optimization ability of ISCSA algorithm are obviously better than that of SCSA algorithm, and the best optimization effect was achieved by using ISCSA algorithm.

Through case study, water resources optimum allocation models were constructed and solved by using the ISCSA algorithm, and the optimal allocation scheme of regional water resources was obtained. It shows from the results that the ISCSA algorithm can achieve high convergence speed, which can meets the operational requirement of multi-objective function, and the results of water resources allocation are more reasonable.

It shows from Table 2 that water supply ability can be greatly improved by using water resources allocation optimization scheme and the ISCSA algorithm. The total water supply ability can reach to 2040.7 million $\mathrm{m}^{3}$ in 2025 , in which the total increased water supply in Xinxiang region will 
reach to 410.0 million $\mathrm{m}^{3}$ compared with that in 2019 . Sewage water reuse will be $18.7 \mathrm{million} \mathrm{m}^{3}$. Rain water collection and utilization will be increased to 12.9 million $\mathrm{m}^{3}$. Considering social and economic development in the region, the benefits of water resources utilization will be raised under application of the water resources optimal allocation scheme. The benefits generated from the water resources optimal allocation scheme will be reached to 153.5 billion Yuan.

It can be forecasted that according to water resources optimal allocation scheme studied in this paper, the amount of groundwater exploitation will be reduced to 735.2 million $\mathrm{m}^{3}$ in 2025 , which means that 217.8 million $\mathrm{m}^{3}$ underground water resources will be saved compared with that in 2009. The water use for eco-environment will be 33.8 million $\mathrm{m}^{3}$.Thus, the eco-environment will be improved. Under the condition of strengthening water saving measures, the balance between water supply and demand in Xinxiang region will be realized.

\section{Declarations}

\section{Funding}

The study was supported by the Natural Science Fund of China (No.50579020).

\section{Conflicts of interest/Competing interests}

There is no conflict of interest in this manuscript.

\section{Availability of data and materials}

All the data and materials in the current study are available from the corresponding author on reasonable request.

\section{Authors' contributions}

The work has not been published before and it is not under consideration for publication anywhere else. The work has been completed by Ke ZHOU. 


\section{Ethics approval}

The author declare that there are no known competing financial interests or personal relationships that could have appeared to influence the work reported in this paper.

\section{Consent for publication.}

All the data in the paper can be published without any competing financial interests or personal relationships that could have appeared to influence the work reported in this paper.

\section{Acknowledgements}

The study was supported by the Natural Science Fund of China (No.50579020).

\section{Reference}

Civicioglu P, Besdok E (2013) A conceptual comparison of the cuckoo-search, particle swarm optimization, differential evolution and artificial bee colony algorithms. Artif Intell Rev 39(4):315-346.

Choi YH. Lee HM. Yoo DG. Kim JH (2017) Self-adaptive multi-objective harmony search for optimal design of water distribution networks. Eng Optim 49(11):1957-1977.

Creaco E. Franchini M (2012). Fast network multi-objective design algorithm combined with a posteriori procedure for reliability evaluation under various operational scenarios. Urban Water $\mathbf{J}$ 9(6):385-399.

Chen Zhe. Yang Kan. Wu Yun. Tang Zijie. Zhang Tianheng. Zhao Youcheng ( 2019). Application research of optimal distribution model of reservoir operation based on SEOA Algorithm. Journal of Water Resources and Water Engineering. 30(05):170-175.

Deb K, Pratap A, Agarwal S, Meyarivan TAMT (2002). A fast and elitist multiobjective genetic algorithm: NSGA-II. IEEE Trans Evol Comput 6(2):182-197.

Eusuff MM, Lansey KE (2003). Optimization of water distribution network design using the shuffled frog leaping algorithm. J Water Resour Plan Manag 129(3):210-225. 
Fallah H, Kisi O, Kim S, Rezaie-Balf M (2019). A new optimization approach for the least-cost Design of Water Distribution Networks: improved crow search algorithm. Water Resour Manag 33(10):3595-3613.

Geem ZW, Kim JH, Loganathan GV (2002). Harmony search optimization: application to pipe network design. Int J Model Simul 22(2):125-133.

Kaveh A, Bakhshpoori T (2016). An efficient multi-objective cuckoo search algorithm for design optimization. Advances in Computational Design 1(1):87-103.

Kivijärvi J, Fränti P, Nevalainen O (2003) Self-adaptive genetic algorithm for clustering. J Heuristics 9(2):113-129.

Ladon A R, White L J,Doolan J A.(1999). Development and resting of an index of stream condition of waterway management in australia.Freshwater,41(1):453-468.

Mohammad rezapour O, Yoosef doost I, Ebrahimi M (2019). Cuckoo optimization algorithm in optimal water allocation and crop planning under various weather conditions (case study: Qazvin plain, Iran). Neural Comput \& Applic 31(6):1879-1892.

Montalvo I, Izquierdo J, Pérez-García R, Herrera M (2010). Improved performance of PSO with self-adaptive parameters for computing the optimal design of water supply systems. Eng Appl Artif Intell 23(5):727-735.

Moosavian N, Lence BJ (2017). Nondominated sorting differential evolution algorithms for multiobjective optimization of water distribution systems. J Water Resour Plan Manag 143(4):04016082.

Naidu MN, Boindala PS, Vasan A, \& Varma MR (2020). Optimization of water distribution networks using cuckoo search algorithm. In Advanced engineering optimization through intelligent techniques (pp. 67-74). Springer, Singapore.

Omid Bozo R G Haddad A S, Mario M A. (2014). Multi-objective quantity-quality reservoir operation in sudden pollution. Water resources Management, 28( 1) : 567-586. 
Prasad TD, Park NS (2004). Multi-objective genetic algorithms for design of water distribution networks. J Water Resour Plan Manag 130(1):73-82.

Razmkhah H, Abrishamchi A, Torkian A. (2010). Evaluation of spatial and temporal variation in water quality by pattern recognition techniques: a case study on Jajrood River ( Tehran, Iran). Journal of Environmental Management, , 91 ( 4 ) :852-860.

Saleh SH, Tanyimboh TT (2014). Optimal design of water distribution systems based on entropy and topology. Water Resour Manag 28(11):3555-3575.

Salman A, Engelbrecht AP, Omran MG (2007). Empirical analysis of self-adaptive differential evolution. Eur J Oper Res 183(2):785-804.

Solihin MI, Zanil MF (2016). Performance comparison of cuckoo search and differential evolution algorithm for constrained optimization. In IOP conference series: materials science and engineering (Vol. 160, No. 1, p. 012108). IOP publishing.

Tanyimboh TT, Czajkowska A (2018). Self-adaptive solution-space reduction algorithm for multi-objective evolutionary design optimization of water distribution networks. Water Resour Manag 32(10):3337-3352.

Vasan A, Simonovic SP (2010). Optimization of water distribution network design using differential evolution. J Water Resour Plan Manag 136(2):279-287.

Whited D C, Kimball J S, Lucotch J A. (2012). A river scape analysis tool developed to assist wild salmon conservation across the North Pacific Rim. Fisheries. 37( 7) : 305-314.

Wang Q, Guidolin M, Savic D, Kapelan Z (2015). Two-objective design of benchmark problems of a water distribution system via MOEAs: towards the best-known approximation of the true Pareto front. J Water Resour Plan Manag 141(3):04014060.

Yang XS (2014). Cuckoo search and firefly algorithm: overview and analysis, In cuckoo search and firefly algorithm (pp. 1-26). Springer, Cham. 
Yasar M (2016). Optimization of reservoir operation using cuckoo search algorithm: example of Adiguzel Dam, Denizli, Turkey. Mathematical Problems in Engineering 2016:1-7.

Zheng F, Zecchin AC, Simpson AR (2013). Self-adaptive differential evolution algorithm applied to water distribution system optimization. J Comput Civ Eng 27(2):148-158. 
Figures

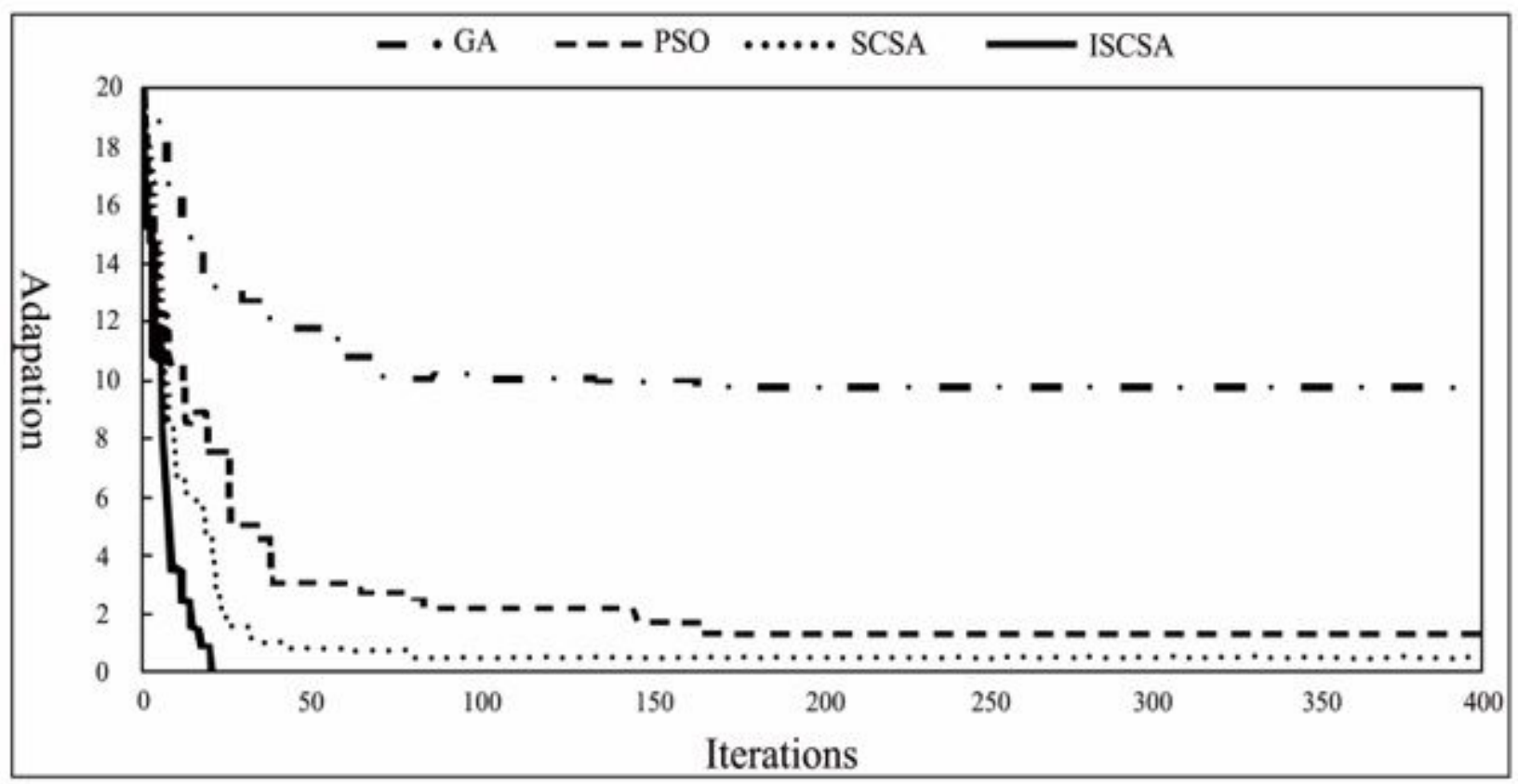

Figure 1

Convergence process diagram of different algorithms

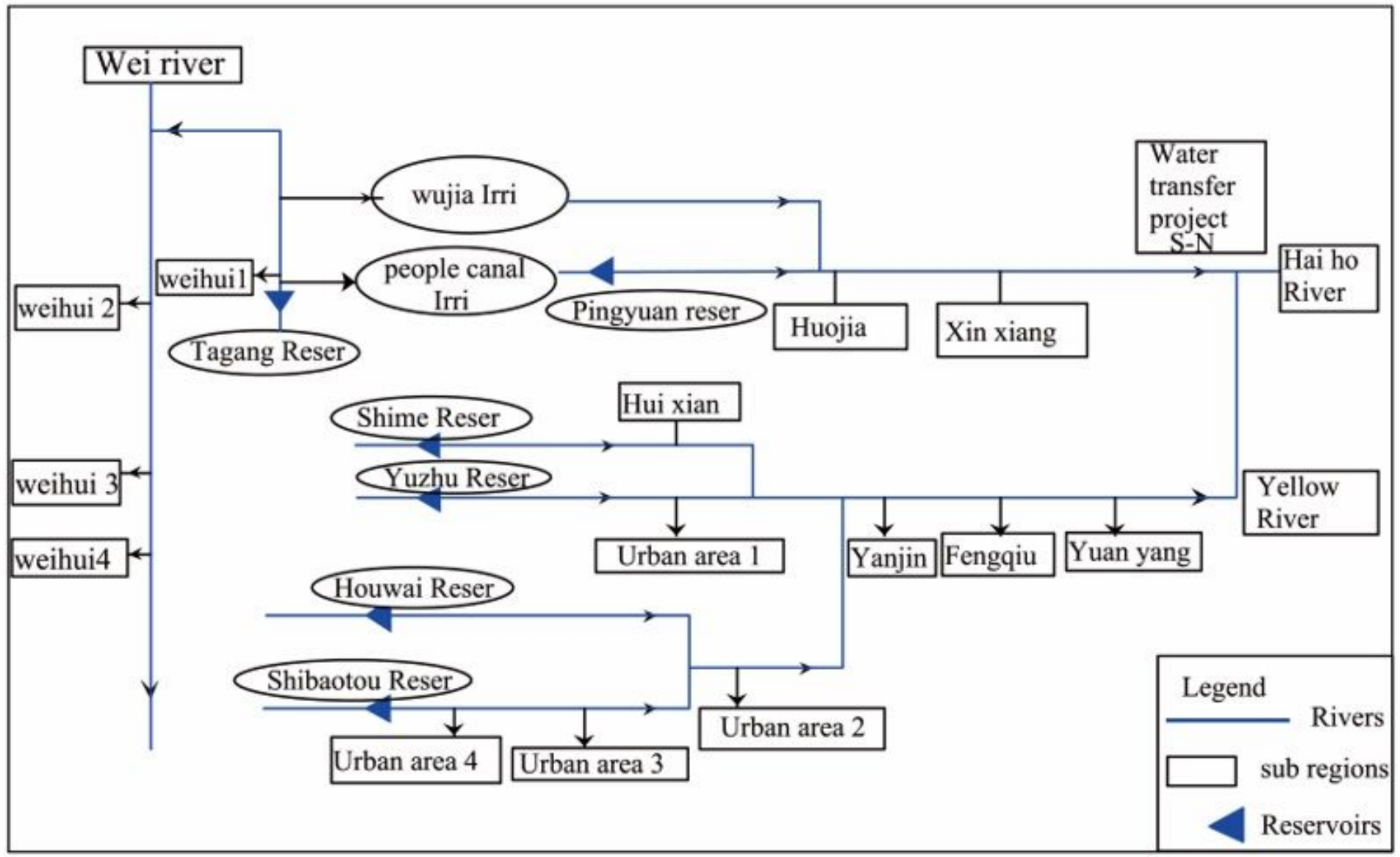


Figure 2

Generalization schematic of water supply nodes in Xinxiang water supply region

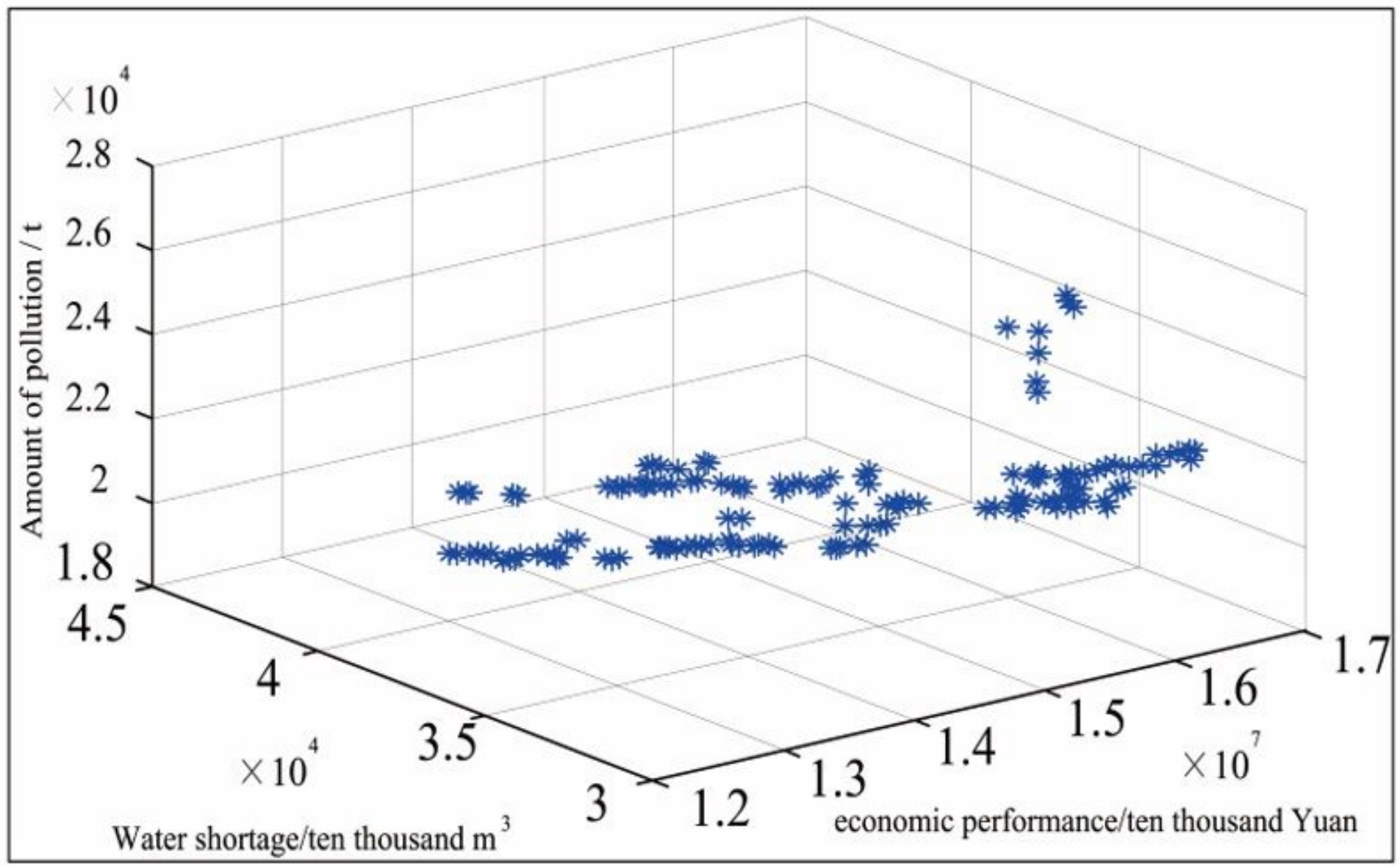

Figure 3

Optimal solution set of SCSA algorithm 


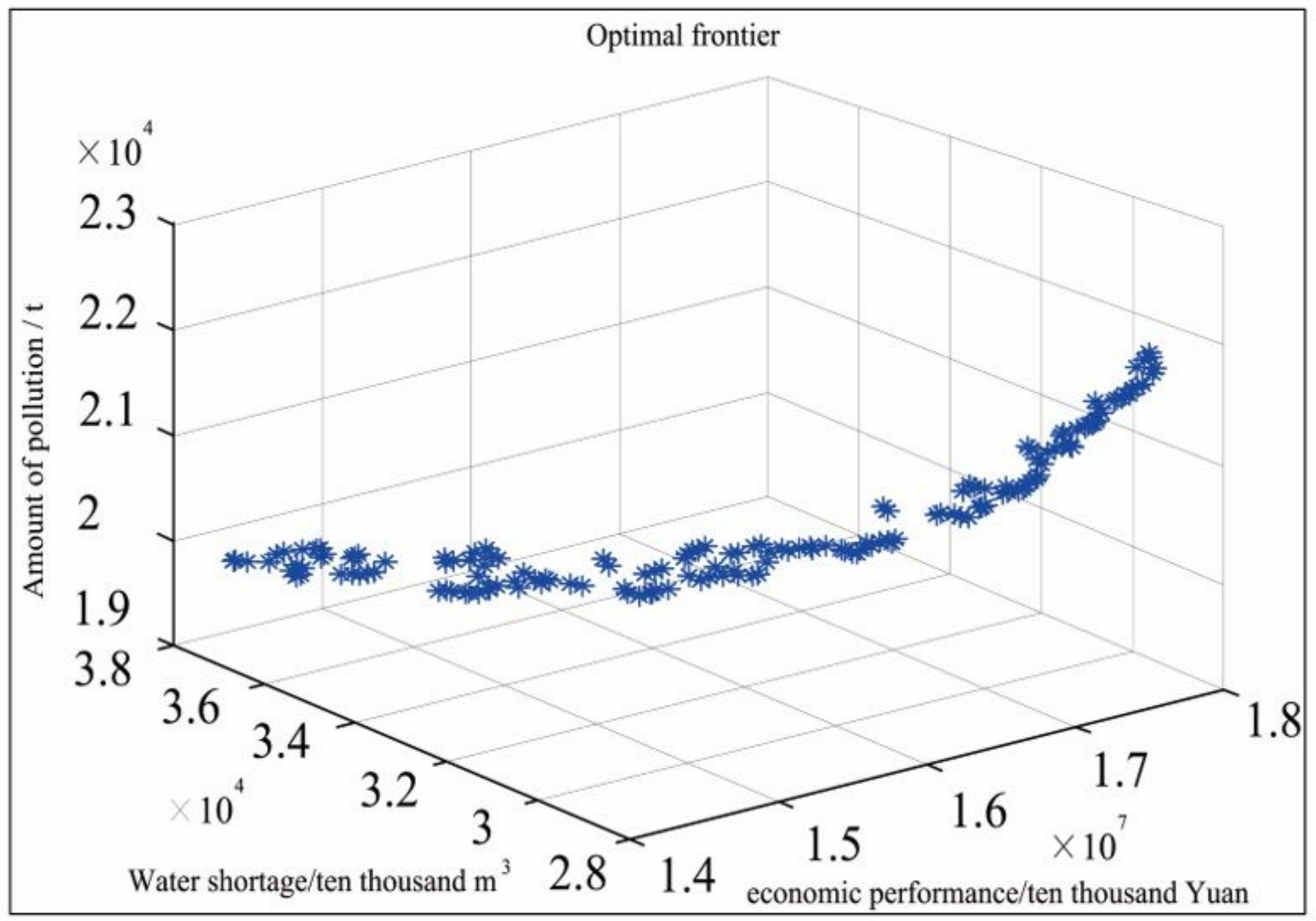

Figure 4

Optimal solution set of ISCSA algorithm 